\title{
Synthesis of Pyrimidines from Propargylic Hydroxylamines
}

Gategory

Synthesis of

Heterocycles

\section{Key words}

pyrimidines

enaminones

propargylic

hydroxylamines<smiles>[R]C#CC([R])N([14CH3])O</smiles>
$\mathrm{NaOH}(10 \mathrm{~mol} \%), \mathrm{MeCN}, 50^{\circ} \mathrm{C}, 1 \mathrm{~h}$

$\mathrm{R}^{1}=\mathrm{Ph}$, 3-Tol, 4-Tol, 2- $\mathrm{FC}_{6} \mathrm{H}_{4}, 4-\mathrm{FC}_{6} \mathrm{H}_{4}, 4-\mathrm{ClC}_{6} \mathrm{H}_{4}, 4-\mathrm{BrC}_{6} \mathrm{H}_{4}, 4-\mathrm{PhC}_{6} \mathrm{H}_{4}, 3-\mathrm{BrC}_{6} \mathrm{H}_{4}$, 3- $\mathrm{MeOC}_{6} \mathrm{H}_{4}$, 1-Naph, 2-Naph, thiophen-2-yl $\mathrm{R}^{2}=\mathrm{Me}, i-\mathrm{Pr}, n-\mathrm{Bu}, \mathrm{Ph}, 4-\mathrm{Tol}$

FAILS when $\mathrm{R}^{1}=2$-Tol or $\mathrm{R}^{2}=t$-Bu

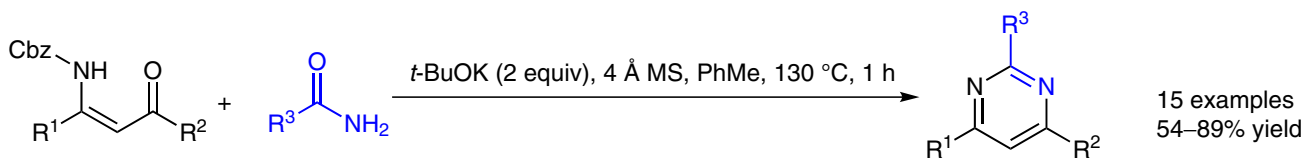

$\mathrm{R}^{3}=\mathrm{Ph}, 4-\mathrm{BrC}_{6} \mathrm{H}_{4}, 4-\mathrm{O}_{2} \mathrm{NC}_{6} \mathrm{H}_{4}$, thiophen-2-y

Significance: Reported is a highly stereoselective access to $\beta$-enaminones based on base-catalyzed isomerization of propargylic hydroxylamines, obtained by $\mathrm{FeCl}_{3}$-catalyzed substitution of propargylic alcohols with Cbz-protected hydroxylamines. $\mathrm{NaOH}$ (10 mol\%) was the optimal base to achieve the isomerization, although other inorganic bases were successful as well. An organic base $\left(\mathrm{Et}_{3} \mathrm{~N}\right)$ did not afford any product and a larger amount of $\mathrm{NaOH}$ was detrimental to the reaction. DFT calculations and additional experiments were undertaken to understand the mechanism, which apparently is initiated by the $\beta$-elimination of the hydroxyl group. The synthesized enaminones are utilized in a reaction with aryl amides to afford pyrimidines in moderate to good yield. Use of aryl nitriles instead of aryl amides resulted in low yields of the pyrimidine products.
Comment: $\beta$-Enaminones are versatile compounds exhibiting pharmacological properties and constituting building blocks for the synthesis of natural products and heterocycles (J. J. Neumann, M. Suri, F. Glorius Angew. Chem. Int. Ed. 2010, 49, 7790), such as pyrimidines. The current report demonstrates the synthesis of enaminones in a stereospecific fashion from inexpensive starting materials under simple and mild reaction conditions in high yield. The utility of enaminones in the synthesis of pyrimidines is well appreciated and in the present report one synthesis of a pyrimidine is also performed on a gram scale. 